\title{
Prevalence of Tuberculosis in District Khar Bajaur Agency, Khyber Pakhtunkhwa Pakistan
}

Sulaiman Shams ${ }^{1}$, Abdur-Rahman' ${ }^{1}$, Abdul Haq ${ }^{2}$, Hammad Hassan' ${ }^{1}$ Sahib Gul Afridi' ${ }^{1}$ and Abdul Wadood ${ }^{{ }^{*}}$

${ }^{1}$ Department of Biochemistry, University College of Science, Shankar, Abdul Wali Khan University Mardan, Khyber Pakhtunkhwa, Pakistan. ${ }^{2}$ District Head Quarter Hospital Khar Bajaur Agency, Khyber Pakhthunkhwa, Pakistan.

\begin{abstract}
Background: Mycobacterium tuberculosis (TB) are a slow-growing facultative intracellular parasite. TB is one of the most common infectious diseases of developing countries including Pakistan. TB is commonly diagnosed by microscopic examination of spontaneously expectorated sputum.

Objective: To find out the prevalence of tuberculosis in the District Khar Bajaur Agency, Khyber Pakhtunkhwa, Pakistan.

Methods: A cross-sectional study was conducted in the District hospital Khar Bajaur Agency, Khyber Pakhtunkhwa, Pakistan from 1st January 2011 to $31^{\text {th }}$ December 2012. There were 1173 patients with $662(56.43 \%)$ males and 511 $(43.57 \%)$ female screened by using sputum smear microscopy. The data were distributed according to the gender, age, weight, past history and treatment of Tuberculosis infection.

Result: The overall prevalence was $33.08 \%$ (388/1173). Out of all affected samples $206(31.12 \%)$ were male and $182(35.62 \%)$ were females. The highest prevalence $48.74 \%$ (99/232) was recorded in 11-20 year age ranges while the lowest $19.82 \%$ (45/227) was recorded in age ranges $01-10$ year.

Conclusion: There is a high prevalence in the selected area due to the lack of migration and war on terrorism, poor medical facility and lack of awareness. It was concluded that Pulmonary TB is the most common prevailing disease in the rural communities in Khar Bajaur Agency, and high incidence was recorded in female as compared to male. There is an urgent need for strategic planning in private and government sector to overcome the high prevalence of tuberculosis infection. In order to reduce the prevalence of Tuberculosis in backward areas of the world, there is an urgent need for strategic planning in private and government sector to overcome the high prevalence of tuberculosis infection.
\end{abstract}

Keywords: Tuberculosis; Bajaur; Prevalence; Hospital; Infection

\section{Introduction}

Tuberculosis is an infectious, chronic disease caused by Mycobacterium tuberculosis [1]. It is the main problem in public health. In developing countries, among infectious diseases, TB is one of the leading causes of mortality and morbidity among all ages and Over $95 \%$ of TB deaths occur in low- and middle-income countries. $\mathrm{TB}$ is among the top three causes of death for women aged 15 to 44 $[2,3]$. It is estimated approximately $1.7 \times 10^{5}$ children die due to the T.B. annually, worldwide [4]. Pakistan ranked $6^{\text {th }}$ worldwide in abundance in T.B. prevalence [5]. T.B. is more common in developed countries at older ages (above 50), while in developing countries, it is common under 50 years of individuals [6]. The overall prevalence in Pakistan is above $1 \%$ account for 1.5 million of the total population and annually about $2.6 \times 105$ new cases appear and roughly about $25 \%$ of the cases are never diagnosed in the country [7]. From different reports it is estimated that approximately $1.7 \times 10^{5}$ children die annually due to T.B. infection. It is thought that T.B. is fourth major cause of all deaths in Pakistan. There is little study reported on gender infection, but there is difference in gender infection. But it is estimated that women have great progression of infection of tuberculosis, but male in most countries are more affected than females [8]. The data so far in the region of Khyber Paktunkhwa (KPK) and northern areas of Pakistan are very less conclusive. The positive smear cases for pulmonary T.B. were $557 / 10,000$ in the village of northern area [9] while the KPK prisoner study shows $48 \%$ prevalence [1]. It is well known that TB spread to different organs and locations within the body, such as brain, bones, abdomen, heart, lymphatic system, urinary tract and lungs [10]. General for the diagnostic of tuberculosis Culture studies, chest radiographic findings and sputum smear, microscopic methods were used [11].
There is no valuable study conducted to detect the prevalence of T.B. in the District Khar Bajaur Agency, KPK. This hospitalized based study shows the prevalence of Tuberculosis among the population of District Khar Bajaur Agency, KPK.

\section{Objective}

The present study aimed to determine the prevalence of $\mathrm{TB}$ infection in District Khar Bajaur Agency, Khyber Pakhtunkhwa (KPK), Pakistan.

\section{Methods}

A detailed study was conducted in the District hospital Khar Bajaur Agency, Khyber Pakhtunkhwa (KPK), Pakistan from $1^{\text {st }}$ Jan 2011 to $31^{\text {st }}$ Dec 2012. Initial screenings of 14350 patients were recorded for the symptoms of T.B. out of these patients, 1173 were diagnosed with T.B. while the rest were excluded from the study.

For each patient three specimens of sputum were collected and

*Corresponding author: Abdul Wadood, Department of Biochemistry, University College of Sciences, Shankar Abdul Wali Khan University Mardan-23200, Khyber Pakhtunkhwa, Pakistan, Tel: +92-937-542195; Fax: +92-937-542195; E-mail: awadood@awkum.edu.pk

Received February 18, 2014; Accepted March 11, 2014; Published March 15 2014

Citation: Shams S, Rahman A, Haq A, Hassan H, Afridi SG, Wadood A (2014) Prevalence of Tuberculosis in District Khar Bajaur Agency, Khyber Pakhtunkhwa Pakistan. Biochem Anal Biochem 3: 148. doi: 10.4172/2161-1009.1000148

Copyright: ( 2014 Shams S, et al. This is an open-access article distributed under the terms of the Creative Commons Attribution License, which permits unrestricted use, distribution, and reproduction in any medium, provided the original author and source are credited. 
examined by microscopy by means of Ziehl-Neelson staining method. First sputum sample was taken after coughing, $2^{\text {nd }}$ sputum on the second day and $3^{\text {rd }}$ sputum sample was taken on the third day. The result with at least two positive smears was identified as a positive tuberculosis case, while one or no positive smear is diagnosed as negative case for tuberculosis infection. Each patient data was recorded such as gender, age, weight, past history of T.B. infection and its treatment.

The patients were classified according to the history of previous treatment, severity of disease and the result of smear pattern. A patient whose has never been diagnosed with T.B., or have been on anti-TB treatment for less than four weeks was considered as New (N). Relapse (R): A patient who has been declared cured or treatment completed for any form of T.B. in the past, but who reports back to the health service and is found to be sputum smear-positive or culture positive. Treatment after previous treatment failure (F): A patient who, while on treatment remained sputum smear-positive or became sputum smear-positive at the end of the five months or more, after commencing treatment. Treatment after default (did not complete previous treatment) (D): A patient who had previously been recorded as defaulted from treatment and returns to the health service with smear-positive sputum. Transfer in (T): A patient who is transferred from another district to continue treatment. Other $(\mathrm{O})$ : A patient who does not fit into any of the above categories.

\section{Statistical analysis}

Data were analyzed by using SPSS Ver. 16 software and parameter was represented in tabular and diagrammatic form using Microsoft Excel 2010.

\section{Results}

During the study period there were a total of 1173 patients screened for T.B. infection. Out of 1173 patients there were 662 (56.43\%) males and 511 (43.56\%) female and Out of 388 infected patients 206 (31.12\%) were male and $182(35.62 \%)$ were females (Table 1$)$. The overall prevalence of T.B. infection in this hospitalized based study population was $33.08 \%(388 / 1173)$. Of 388 patients, higher prevalence $48.74 \%(99 / 232)$ was recorded in age ranges from $11-20$ year, while the lowest were recorded in $19.82 \%$ (45/227) was recorded in age ranges from 01-10 year (Table 2). The total prevalence in 2011 was $31.71 \%$ and increased in 2012 to $34.49 \%$.

\section{Discussion}

Tuberculosis in many cases have high morbidity and morbidity among different infectious diseases [12]. Worldwide about 3.5 million cases (44\%) appeared annually [13]. This study was conducted in the district Bajaur agency and the overall prevalence in our study was $33.08 \%$. The people of this area like other areas are afraid to disclose the diagnosis due to fear of discrimination by the community and think that once this infection occurs then it leads to death. The main causes of high prevalence are migrating to camps due to political instability in the region, lack of education, poor medical facilities and lack of awareness among the population [14].

The perceived symptoms of T.B. are generally referred to as simple cough or prolonged fever [15]. Very few respondents talked about weight loss or night sweats. Females are generally unaware of symptoms like blood in the sputum.

Our study shows that there is an increase in the prevalence of T.B. In 2011 the prevalence was $31.71 \%$ and in 2012 it increased to $34.78 \%$, which gives a silent increase in the prevalence of T.B. in population.

Our study indicates that based on gender classification T.B. prevalence was recorded high in female $35.62 \%$, compared to male's $31.12 \%$. Our data suggest a direct correlation with the previous findings [16]. This high difference in male/female ratio of T.B. results due to the lack of female education, carelessness, hard work, and poor health care offered by community $[17,18]$. The increased awareness of gender inequalities in health care will hopefully lead to increased research resources and efforts to understand inequities in health and health care use.

A high prevalence $(42.67 \%)$ was determined at the age of $11-20$ years group while the lowest prevalence (19\%) was determined in $01-$ 10 age groups. These results are consistent with the previous findings [16]. Efforts are needed to improve the knowledge of doctors and urgent need of effective Standardized treatment protocol to support with National T.B. control program. There is need of educational improvement, health facility and increase awareness in the population.

\begin{tabular}{|l|l|l|l|l|}
\hline Year & & No of Samples & & Affected \\
\hline 2011 & Males & 344 & 101 & \% age \\
\hline & Females & 252 & 88 & 29.36 \\
\hline & Total & 596 & 189 & 34.92 \\
\hline 2012 & Males & 318 & 105 & 31.71 \\
\hline & Females & 259 & 94 & 33.02 \\
\hline & Total & 577 & 199 & 36.29 \\
\hline
\end{tabular}

Table 1: Gender wise prevalence of tuberculosis.

\begin{tabular}{|c|c|c|c|c|c|c|}
\hline Years Ages & $\begin{array}{l}\text { 2011-2012 } \\
\text { Total screen }\end{array}$ & Total affected (\%age) & $\begin{array}{l}2011 \\
\text { Male affected (\%age) }\end{array}$ & Female affected (\%age) & $\begin{array}{l}2012 \\
\text { Male affected (\%age) }\end{array}$ & Female affected (\%age) \\
\hline 01-10 & 227 & $45(19.82 \%)$ & $17(24.28 \%)$ & $12(26.66 \%)$ & $10(14.92 \%)$ & $6(13.33 \%)$ \\
\hline $11-20$ & 232 & $99(42.67 \%)$ & $21(32.81 \%)$ & $20(40.81 \%)$ & $32(50 \%)$ & $26(47.27 \%)$ \\
\hline $21-30$ & 268 & $98(36.56 \%)$ & $26(31.32 \%)$ & $23(36.50 \%)$ & $23(34.32 \%)$ & $26(47.27 \%)$ \\
\hline $31-40$ & 165 & $50(30.30 \%)$ & $13(30.95 \%)$ & $10(28.57 \%)$ & $12(27.27 \%)$ & $15(34.09 \%)$ \\
\hline $41-50$ & 107 & $37(34.57 \%)$ & $12(36.36 \%)$ & $10(38.46 \%)$ & $8(30.76 \%)$ & $7(31.81 \%)$ \\
\hline $51-60$ & 98 & $32(32.65 \%)$ & $6(26.08 \%)$ & $7(31.81 \%)$ & $12(38.70 \%)$ & $7(31.81 \%)$ \\
\hline $61-70$ & 50 & $20(40 \%)$ & $5(27.77 \%)$ & $4(44.44 \%)$ & $4(40 \%)$ & $7(53.84 \%)$ \\
\hline $71-80$ & 26 & $7(26.92 \%)$ & $1(9.090 \%)$ & $2(66.66 \%)$ & $4(44.44 \%)$ & $0(0 \%)$ \\
\hline Total & 1173 & $388(33.07 \%)$ & $101(29.36 \%)$ & $88(34.92 \%)$ & $105(33.01 \%)$ & $94(36.29 \%)$ \\
\hline
\end{tabular}

Table 2: Prevalence of tuberculosis at age and year based. 
Citation: Shams S, Rahman A, Haq A, Hassan H, Afridi SG, Wadood A (2014) Prevalence of Tuberculosis in District Khar Bajaur Agency, Khyber Pakhtunkhwa Pakistan. Biochem Anal Biochem 3: 148. doi: 10.4172/2161-1009.1000148

Page 3 of 3

\begin{tabular}{|l|l|l|l|l|l|l|}
\hline & \multicolumn{5}{c|}{ TYPES OF PATIENTS } \\
\hline YEAR & N & R & F & D & T & 3 \\
\hline 3-Jul & 169 & 9 & 7 & 0 & 1 \\
\hline 4-Jul & 170 & 20 & 6 & 0 & 0 \\
\hline TOTAL & 339 & 29 & 13 & 0 & 3 \\
\hline
\end{tabular}

Table 3: Classification based on tb patients type.

$\mathrm{N}$ : New, R: Relapse, F: Treatment after previous treatment failure, D: Did not complete previous treatment, T: Transfer in, O: Other.

\section{Acknowledgement}

Sputum donors in the present study are greatly acknowledged and appreciated.

\section{References}

1. Hussain H, Akhtar S, Nanan D (2003) Prevalence of and risk factors associated with Mycobacterium tuberculosis infection in prisoners, North West Frontier Province, Pakistan. Int J Epidemiol 32: 794-799.

2. World Health Organization. Tuberculosis. WHO 2013. http://www.who.int/ mediacentre/factsheets/fs104/en/. (accessed October 2013).

3. Raviglione MC, Dye C, Schmidt S, Kochi A (1997) Assessment of worldwide tuberculosis control. WHO Global Surveillance and Monitoring Project. Lancet 350: 624-629.

4. Kathy A (1996) Tuberculosis and children: the missing diagnosis. A specia supplement to child health dialogue. AHRTAG London 1: 1-5.

5. The Express tribune. With the international network times 2011; [http:// tribune.com.pk/story/292170/pakistan-ranks-6th-among-22-high-burden-tb. countries/]15Novermber 2011).

6. Goodyear HM, Moore-Gillon JC, Price EH, Larcher VF, Savage MO, et al. (1993) Mycobacterial infection in an inner city children's hospital. Arch Dis Child 69: 229-231.

7. Khan JA, Malik A (2003) Tuberculosis in Pakistan: Are We losing the battle? Journal of Pakistan Medical Association 234: 1-3. [http://jpma.org.pk/full_ article_text.php?article_id=234]

8. Rhines AS (2013) The role of sex differences in the prevalence and transmission of tuberculosis. Tuberculosis (Edinb) 93: 104-107.

9. Alvi AR, Hussain SF, Shah MA, Khalida M, Shamsudin M (1998) Prevalence of pulmonary tuberculosis on the roof of the world. Int $\mathrm{J}$ Tuberc Lung Dis 2: 909-913.
10. Shah S, Miller A, Mastellone A, Kim K, Colaninno P, et al. (1998) Rapid diagnosis of tuberculosis in various biopsy and body fluid specimens by the AMPLICOR Mycobacterium tuberculosis polymerase chain reaction test. Chest 113: $1190-1194$

11. Soini H, Musser JM (2001) Molecular diagnosis of mycobacteria. Clin Chem 47: 809-814.

12. Toole MJ, Galson S, Brady W (1993) Are war and public health compatible? Lancet 341: 1193-1196.

13. Dye C, Scheele S, Dolin P, Pathania V, Raviglione MC (1999) Consensus statement. Global burden of tuberculosis: estimated incidence, prevalence, and mortality by country. WHO Global Surveillance and Monitoring Project. JAMA 282: $677-686$

14. Ali SS, Rabbani F, Siddiqui UN, Zaidi AH, Sophie A, et al. (2003) Tuberculosis: do we know enough? A study of patients and their families in an out-patient hospital setting in Karachi, Pakistan. Int J Tuberc Lung Dis 7: 1052-1058.

15. Agboatwalla M, Kazi GN, Shah SK, Tariq M (2003) Gender perspectives on knowledge and practices regarding tuberculosis in urban and rural areas in Pakistan. East Mediterr Health J 9: 732-740.

16. Ullah S, Shah SH, Aziz-ur-Rehman, Kamal A, Begum N, et al. (2008) Extrapulmonary tuberculosis in Lady Reading Hospital Peshawar, NWFP, Pakistan: survey of biopsy results. J Ayub Med Coll Abbottabad 20: 43-46.

17. Hoa NP, Thorson AE, Long NH, Diwan VK (2003) Knowledge of tuberculosis and associated health-seeking behaviour among rural Vietnamese adults with a cough for at least three weeks. Scand J Public Health Suppl 62: 59-65.

18. Enwuru CA, Idigbe EO, Ezeobi NV, Otegbeye AF (2002) Care-seeking behavioural patterns, awareness and diagnostic processes in patients with smear- and culture-positive pulmonary tuberculosis in Lagos, Nigeria. Trans R Soc Trop Med Hyg 96: 614-616. 